\title{
Total Uterine Necrosis: A Complication of B-Lynch Suture
}

Savita A Somalwar, Sulbha A Joshi, Anuja V Bhalerao, Anjali S Kawthalkar

Sheela Jain, Sadhana Mahore

\begin{abstract}
Uterine atony is the most common cause of postpartum hemorrhage (PPH) which leads to maternal mortality and morbidity. Herewith reporting a case of 35-year-old woman who underwent cesarean section for transverse lie with hand prolapse. She had atonic PPH for which uterine artery ligation was done along with B-lynch suture. She had subinvolution of uterus secondary to multiple abscesses in uterine wall. She underwent subtotal hystrectomy. Hispathology showed uterine necrosis.
\end{abstract}

Keywords: Uterine necrosis, B-lynch suture, PPH.

How to cite this article: Somalwar SA, Joshi SA, Bhalerao AV, Kawthalkar AS, Jain S, Mahore S. Total Uterine Necrosis: A Complication of B-Lynch Suture. J South Asian Feder Obst Gynae 2012;4(1):61-63.

\section{Source of support: Nil}

\section{Conflict of interest: None declared}

\section{INTRODUCTION}

Uterine atony, or failure of the uterus to contract adequately after childbirth, is the most common case of postpartum hemorrhage (PPH). ${ }^{1}$ Most of the cases of atonic PPH respond to uterotonic drugs. However, few patients will require surgical intervention. Traditionally, the various modalities for atonic PPH not responding to uterotonic drugs include uterine packing, stepwise devascularization of uterus, internal iliac artery ligation and if this fail, obstetric hysterectomy. Definative surgical management of PPH with hysterectomy results in complete inability to host a future pregnancy. B-lynch suture and its modifications have added a new conservative modality in the hands of treating obstetricians before proceeding to obstetric hysterectomy. ${ }^{2}$

\section{CASE REPORT}

A 35-year-old woman reported to our hospital in emergency with history of cesarean section done 17 days back with persistence of distension of abdomen since cesarean section. Her discharge card revealed that indication for cesarean section was $\mathrm{G}_{6} \mathrm{P}_{5} \mathrm{~L}_{3} \mathrm{D}_{2}$ with transverse lie with hand prolapse. Intraoperatively, there was atonic PPH and hence uterine artery ligation was done alongwith B-lynch suture. Same day, she was referred to Government Medical College, Nagpur for severe anemia where she received 4 units of blood transfusion and her stay at Government Medical College was otherwise uneventful and was discharged after 1 week. Ten days after discharge from Government Medical College she came to our hospital with complaints of persistent distension of abdomen and weakness. There was no history of fever, bleeding per vaginam, vomiting and loose motions. Her vitals were stable except she was extremely pale. On per abdominal examination uterus was enlarged to 30 weeks pregnant uterine size and was soft in consistency. It was nontender with restricted mobility. On per speculum examination os was open with foul smelling discharge. Per vaginal examination revealed that uterus was subinvoluted enlarged to 30 weeks pregnant uterine size, nontender with restricted mobility and internal os was open. She was investigated $\mathrm{Hb}-3 \mathrm{gm} \%$, TLC, DLC, urine routine, LFT, KFT-WNL. Vaginal swab showed growth of klebsiella organism. USG abdomen was suggestive of large endometrial collection showing numerous air pockets.

She received 4 units blood transfusion and antibiotics preoperatively and was prepared for evacuation and SOS hysterectomy. Evacuation was done under USG guidance. There was no bleeding or retained placental bits. Uterine cavity was empty. So decision was taken of abdominal hysterectomy. Intraoperatively, adhesions were present between parietal peritoneum, uterus, bowel and bladder. Uterus was necrosed and enlarged to 30 weeks pregnant uterine size. There was evidence of abscesses in myometrium. Also there was evidence of peeling of wall of uterus. Ovaries were normal. Subtotal hysterectomy was done. Intraoperatively, she received 4 units of blood transfusion. Abdominal drain was kept for 5 days. Postoperative period was uneventful. Stich removal was done on 10th postoperative day. Histopathology of uterus was suggestive of extensive infarction with acute inflammation. Patient was discharged from hospital in a stable condition.

\section{DISCUSSION}

B-lynch suture technique is one of the conservative surgical procedure done in atonic PPH (Fig. 1). The suturing technique involves a pair of vertical brace sutures around the uterus, essentially to oppose the anterior and posterior uterine walls. These brace sutures work by direct application of pressure on the placental bed bleeding and by reducing the blood to uterus.

The success rate of B-lynch suture, in avoiding hysterectomy is $86.4 \%,{ }^{3}$ and the procedure has been widely recommended to control PPH. ${ }^{4}$ Successful pregnancy after B-lynch suture is possible and seven uneventful pregnancies after uterine compression sutures were reported in the largest review. Murat Api et $\mathrm{al}^{5}$ also reported a successful pregnancy after B-lynch suture and hypogastric artery ligation.

Isolated complications of conservative surgical management of $\mathrm{PPH}$, including compression and ligation techniques have been reported. Akoury and Sherman ${ }^{6}$ reported a patient who required both B-lynch and Cho compression sutures. Uterine synechiae developed early in the postoperative period and were subsequently resected hysteroscopically. After the patient carried a full term pregnancy 1 year later, an area of full thickness myometrial necrosis was noted which required 
operative resection. The authors hypothesized that pressure produced by the compression sutures may have caused progressive myometrial necrosis (Figs 2 and 3). Partial ischemic necrosis of uterus has also been described by Joshi VM, Shrivastava $\mathrm{M}^{7}$ Treloar EJ et $\mathrm{al}^{8}$ and Gottlieb AG et al. ${ }^{9}$

A case of pyometra after hemostatic square suture was described by Ochoa $\mathrm{M}$ et al. ${ }^{10}$ Erosion of B-lynch suture through the uterine wall at 6 weeks postpartum has also been reported by Groetgul CA et al. ${ }^{11} \mathrm{Wu} \mathrm{H}$ et al ${ }^{12}$ reported uterine cavity synchiae after Cho suture technique. A case of Asherman syndrome was reported by Ciaran $\mathrm{A}^{13}$ et al after B-lynch and uterine aretery ligation.

In this case report, woman had developed uterine necrosis secondary to B-lynch suture. Uterine necrosis could be because of too tight sutures which may compromise the blood supply of uterus. She also had myometrial abscesses. Hysterectomy was mandatory in this case as otherwise she would have landed up in septicemia and an added maternal mortality. Ideally in her case primary surgery should have been hysterectomy as she was 6 para and uterine conservation was not mandatory.

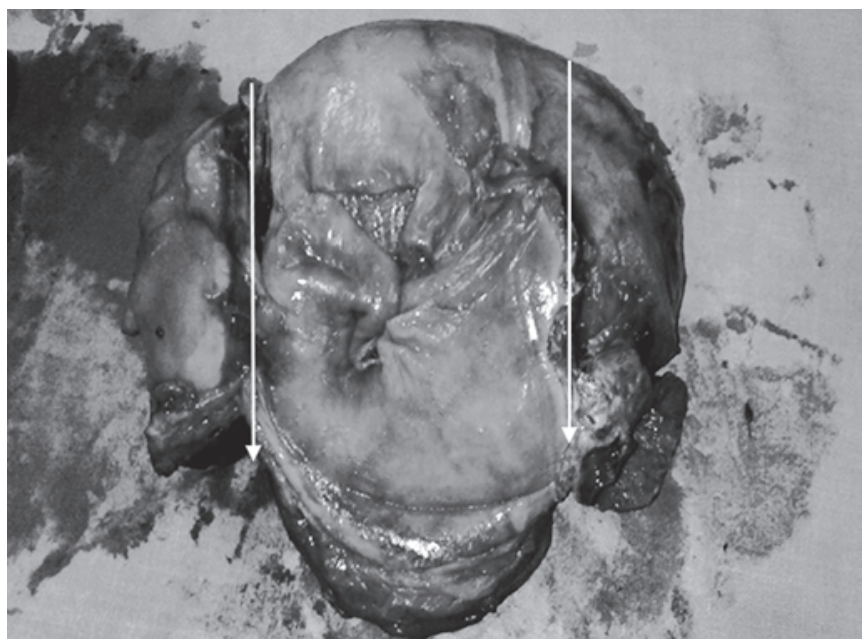

Fig. 1: Specimen of uterus with arrows showing the site of B-lynch suture

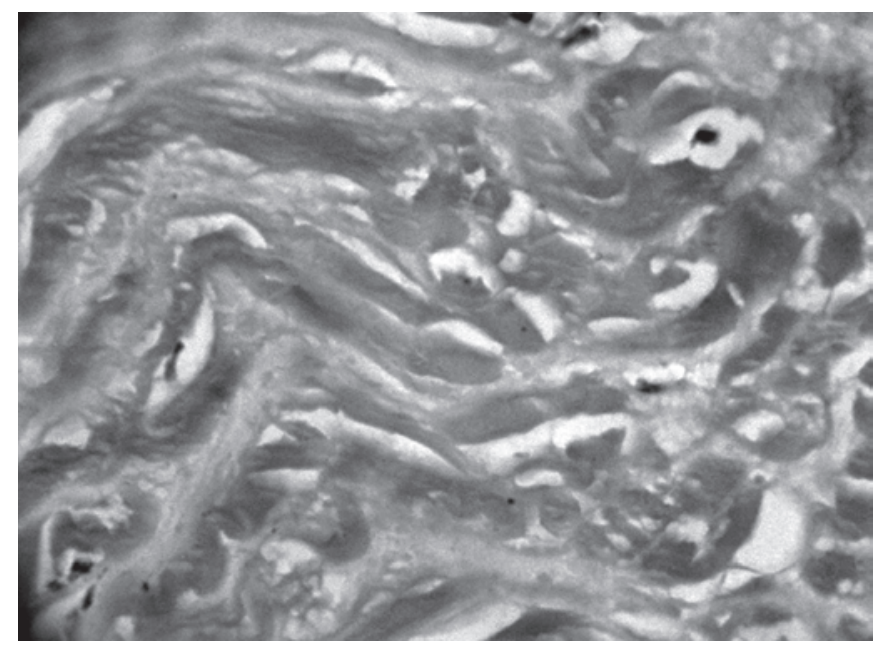

Fig. 2: Histopathology view showing infarction of myometrial smooth muscle



Fig. 3: Histopathological view showing infarction and inflammatory response in myometrium

Although the B-lynch suture is very successful in preventing the need for hysterectomy during intractable PPH unresponsive to medical management, the effects of B-lynch suture on future fertility potential require further investigation. Although isolated case reports of successful pregnancies are reassuring, patients and physicians need to be aware of the potential complications. Failures and short and long-term consequences of compression sutures need to be reported. Careful follow-up of women in whom compression sutures are performed will help in detecting various complications.

\section{REFERENCES}

1. Khan KS, Wojclyle D, Say L, Gulmazoglu AM, Van Look PF. WHO analysis of causes of maternal death, a systematic review. Lancet 2006;267:1066-74.

2. B-lynch C, Coker A, Lawal AH, et al. The B-lynch surgical technique for the control of massive postpartum haemorrhage: An alternative to hysterectomy? Five cases reported. British Journal of Obstetrics and Gynaecology 1997;104:372-75.

3. Baskett TF. Uterine compression sutures for postpartum hemorrhage. Obstet Gynecol 2007;110:68-71.

4. American Congress of Obstetricians and Gynaecologists. ACOG practice bulletin. Clinical management guidelines for obstetrician - gynaecologists. No. 76. Oct 2006: Postpartum hemorrhage. Compend Select Pub 2007;843-51.

5. Murat Api, Olus Api, Murat Yayla. Fertility after B. lynch suture and hypogastric artery ligation. Fertility and Sterility August 2005;84(2):509.

6. Akoury H, Sherman C. Uterine wall partial necrosis following combined B lynch and Cho square sutures for the treatment of primary postpartum hemorrhage. J Obstet Gynaecol Can 2008; 30:421-24.

7. Joshi VM, Shrivastava M. Partial ischaemic necrosis of the uterus following uterine brace compression suture. BJOG 2004;111: 279-80.

8. Treloar EJ, Anderson RS, Andrews HS, Bailey JL. Uterine necrosis following B-lynch suture for primary postpartum hemorrhage. BJOG 2006;113:486-88. 
9. Gottelieb AG, Pandipati S, Davis KM, Gibbs RS. Uterine necrosis: A complication of uterine compression sutures. Obstet Gynecol Aug 2008, 112(2 pt 2):429-31.

10. Ochoa M, Allaire AD, Stitlely ML. Pyometra after haemostatic square suture technique. Obstet Gynecol 2002; Mar 99 (3): 506-09.

11. Grotegut CA, Larsen FW, Jones MR, Livingston E. Erosion of B-lynch suture through the uterine wall: A case report. J Reprod Med Oct 2004; 49(10): 849-52.

12. Wu H, Yeh GP. Uterine cavity synechiae after hemostatic square suturing technique. Obstet Gynecol 2005;105:1176-78.

13. Ciaran A, Goojha MD, Allison case MD, Roger Pierson. Development of Asherman syndrome after conservative surgical management of intractable postpartum hemorrhage. Fertil Steril August 2010;94(3):1098.

\section{ABOUT THE AUTHORS}

\section{Savita A Somalwar}

Lecturer, Department of Obstetrics and Gynecology, NKP Salve Institute of Medical Sciences and Research Centre and Lata Mangeshkar Hospital, Nagpur, Maharashtra, India

\section{Sulbha A Joshi}

Professor and Head, Department of Obstetrics and Gynecology, NKP Salve Institute of Medical Sciences and Research Centre and Lata Mangeshkar Hospital, Nagpur, Maharashtra, India

\section{Anuja V Bhalerao}

Associate Professor, Department of Obstetrics and Gynecology, NKP Salve Institute of Medical Sciences and Research Centre and Lata Mangeshkar Hospital, Nagpur, Maharashtra, India

\section{Anjali S Kawthalkar}

Associate Professor, Department of Obstetrics and Gynecology, NKP Salve Institute of Medical Sciences and Research Centre and Lata Mangeshkar Hospital, Nagpur, Maharashtra, India

\section{Sheela Jain}

Lecturer, Department of Obstetrics and Gynecology, NKP Salve Institute of Medical Sciences and Research Centre and Lata Mangeshkar Hospital, Nagpur, Maharashtra, India

\section{Sadhana Mahore}

Professor and Head, Department of Pathology, NKP Salve Institute of Medical Sciences and Research Centre and Lata Mangeshkar Hospital, Nagpur, Maharashtra, India

\section{CORRESPONDING AUTHOR}

Savita A Somalwar, Lecturer, Department of Obstetrics and Gynecology, Plot No. 264, Bajaj Nagar, West High Court Road Nagpur-440010, Maharashtra, India, Phone: 9158920941, e-mail: somalwar.sa@gmail.com 